\title{
Ecodesign through Environmental Risk Management: A Focus on Critical Materials
}

\author{
Stafford Lloyd ${ }^{1,2}$, Jacquetta Lee ${ }^{2}$, Andrew Clifton ${ }^{1}$, Lucia Elghali ${ }^{2}$ and Chris France ${ }^{2}$ \\ ${ }^{1}$ Life Cycle Engineering, Rolls-Royce plc, Bristol, UK \\ ${ }^{2}$ Centre for Environmental Strategy, University of Surrey, Guildford, UK
}

\begin{abstract}
This paper presents an approach to Ecodesign based on the management of environmental business risks, which are defined as 'stakeholder responses to environmental impacts with the potential to cause harm to business objectives'. Case studies are used to demonstrate the approach, with a particular focus on the management of critical materials. The paper concludes that by using risk, environmental considerations can be integrated into design decisions at Rolls-Royce, although the method contains significant uncertainties. In particular, the paper highlights the complexity of both assessing the supply risk of a material and how this could translate into an impact on the business. The paper also discusses how the risk model could be expanded to address other environmental business hazards.
\end{abstract}

Keywords:

critical materials, risk, environmental risk, life cycle management

\section{INTRODUCTION}

Rolls-Royce provides power systems and services for use in the air, on land and at sea, focusing on four main markets: civil aerospace, defence aerospace, energy and marine. Predominantly, although not exclusively, RollsRoyce's products are based on the gas turbine engine.

The nature of Rolls-Royce's products present several unique barriers to the implementation of ecodesign approaches:

1. Environmental impacts from the 'in-use' phase dominate over the product life cycle. Understandably this is the focus for addressing environmental impacts, although this also means that environmental impacts from other phases of the life cycle can be overlooked.

2. Rolls-Royce's products are designed to have an operational life of up to 50 years. Environmental problems can change significantly in this time and it is difficult to foresee what the next problem might be.

3. Rolls-Royce's products are technically mature. There is very little design freedom to make nonuse phase environmental improvements.

4. Due to the safety critical nature of Rolls-Royce's products, the company uses rigorous design systems to verify product designs against well defined requirements. At the present time, nonuse phase environmental impacts are not comparable within the traditional design space, which means they are largely ignored.
Risk management is used within the Rolls-Royce design system to identify hazards that can impact on design and other business objectives. By translating environmental impacts into an assessment of business risk, barriers to ecodesign can be overcome and non use-phase environmental impacts considered within the design process. This paper presents two case studies that test an approach to ecodesign based on the management of environmental risks. The case studies focus on the use of critical materials, which is linked to the abiotic resource depletion environmental impact category.

As risk is a broad term, the paper first defines what is meant by 'environmental business risk'. Materials criticality is then introduced as a significant risk, using an approach developed by the European Commission to highlight materials that are of concern. Based on knowledge of where these materials are used in RollsRoyce's products, case study risk assessments are then presented, which show how the risks posed by materials criticality can be incorporated into standard design decisions. The paper discusses the practicalities of the risk based approach, in light of significant uncertainties that will be inherent in any system that seeks to look into the future. The paper also discusses how the risk model could be expanded to address other environmental business hazards.

\section{ENVIRONMENTAL RISK MANAGEMENT}

Environmental risk management adopts a business risk perspective, concerned with identifying hazards that can impact on business objectives [1]. It is based on the 
observation of a cause-effect cycle between the environmental impacts of a business' operations and products and stakeholder responses to these impacts (whether they are actual, potential or perceived) which seek to reduce them and can impact on business objectives [2]. The stakeholder responses to environmental impacts, with the potential to cause harm to business objectives, are defined as 'environmental business hazards'. The environmental business risk is a product of the likelihood of a hazard occurring and the impact it would have on business objectives if it did. There are many sources of environmental business hazard, regulation being a primary example.

Business risk is assessed against objectives, which are generally based upon the provision of products and services and the revenue this provides. It follows that, to assess the risk posed by environmental business hazards, it is necessary to understand how hazards impact on the ability of the business to make and sell products. Risk can be assessed by connecting some feature of the hazard with a feature of the product. Appropriate mitigating actions can then be implemented.

\section{CRITICAL MATERIALS: A SIGNIFICANT ENVIRONMENTAL BUSINESS HAZARD}

A significant environmental business hazard that has been the subject of recent attention is 'critical materials'. The phenomenon is concerned with constraints being placed on the accessibility of material commodities as a result of geological, political and economic factors. Whilst it is not purely an environmental problem, the depletion of abiotic resources is a common impact category within life cycle impact assessment [3], and it falls within the definition of an environmental business hazard.

There are two "dimensions" of materials criticality [4]:

1. Supply risk: identifying and applying factors that can be used to assess the risks to the supply of a material.

2. Economic importance: an assessment of how important the use of a material is in meeting economic goals, which can be also be assessed at a business level e.g. restrictions in the availability of materials can also restrict the ability of a business to make a product.

A material is referred to as critical when it has a high supply risk and is of high economic importance.

The two dimensions of materials criticality need to be applied to understand the business risks posed. These can be achieved through the:

1. Identification and application of a method for assessing supply risk, which identifies materials of concern.

2. Connecting these materials with uses in products to evaluate the risk posed to business objectives.

\subsection{Assessing supply risk}

Several different methods have been developed to assess supply risk [5] [6] [7]. Due to the use of a transparent methodology with available data, this paper focuses on an approach developed by the European Commission (EC) [7]. The EC method applies four metrics to assess supply risk:

1. Monopoly supply: materials that come from few sources are assumed to be higher risk.

2. Governance indicators: materials that are sourced from politically unstable regions are assumed to be higher risk. Governance indicators are merged with the monopoly supply index to highlight where a material's supply is dominated by unstable producing countries.

3. Recycling rate: based on the assumption that the availability of recycled sources lowers risk.

4. Substitutability: materials that are substitutable are likely to be more flexible to changes in demand, reducing risk.

Monopoly supply is measured using the HerfindahlHirschmann Index (HHI), which is the sum of the squares of the supply percentages (S) of producing countries (c) for a given material (i), as shown in Eqn. 1:

$$
H H I_{c}=\sum_{c} S_{i c}^{2}
$$

The equation produces a figure between 0 and 10000, a higher number signifying higher risk.

World Governance Indicators (WGI) produced by the World Bank were merged with the HHI to highlight where supply was dominated by an unstable producing region. The WGI scored countries according to 6 categories (including political stability, control of corruption and rule of law), producing a result between 0 and 10. These scores were merged with the HHI as shown in Eqn. 2:

$$
H H I_{W G I}=\sum_{c} S_{i c}^{2} W G I_{c} \quad \text { (Eqn. 2) }
$$

The result produces a score of 0 to 100000 , which was scaled to a value of between 0 and 10 .

The recycling rate used for a material $\mathrm{i}\left(\rho_{\mathrm{i}}\right)$ applied the ratio of current demand met by old scrap. Data on recycling rate is given in the EC report [7].

Substitutability $\left(\sigma_{i}\right)$ for a material i was measured using an index developed through expert judgements (Table 1).

Table 1: Substitutability indices [7]

\begin{tabular}{|l|l|}
\hline Score & \multicolumn{1}{|c|}{ Substitutability } \\
\hline 0 & $\begin{array}{l}\text { Easily and completely substitutable at } \\
\text { no additional cost. }\end{array}$ \\
\hline 0.3 & Substitutable at low cost. \\
\hline 0.7 & $\begin{array}{l}\text { Substitutable at high cost and/or loss of } \\
\text { performance/ }\end{array}$ \\
\hline 1.0 & Not substitutable. \\
\hline
\end{tabular}


All of the metrics were merged into the final equation for supply risk, calculated by material (i):

$$
S R_{i}=\sigma_{i}\left(1-\rho_{i}\right) H H I_{W G I}
$$

The term $\left(1-\rho_{\mathrm{i}}\right)$ is used as a higher recycling rate will reduce supply risk. The result of the supply risk calculation will produce a score of between 0 and 10 by material, with a score of 10 representing the highest possible risk.

SR scores were calculated for 41 materials, 14 being highlighted as potentially critical (Table 2). Both of the highest scores were attributed to materials that have relatively few sources (monopoly supply).

Table 2: The EC 14 (SR scores in bold) [7]

\begin{tabular}{|c|c|}
\hline Rare Earth Elements (REE) [4.9] & Indium [2.0] \\
\hline Platinum Group Metals (PGM) [3.6] & Tungsten [1.8] \\
\hline Niobium [2.8] & Fluorspar [1.6] \\
\hline Germanium [2.7] & Beryllium [1.4] \\
\hline Antimony [2.6] & Graphite [1.3] \\
\hline Magnesium [2.6] & Tantalum [1.1] \\
\hline Gallium [2.5] & Cobalt [1.1] \\
\hline
\end{tabular}

The 14 critical materials highlighted from the EC report and the method for assessing SR solve the first problem of identifying materials that are of concern. To understand the risk, it needs to be identified where these are used in products.

\subsection{Identifying uses of critical materials}

Product data is required to understand the uses of critical materials. Basic data on product content is provided by a standard engineering Bill of Materials (BoM). A BoM is unlikely to be sufficient to identify product features related to all environmental business hazards. Hazards can relate to any impact over the product life cycle, requiring a life cycle view. However, a BoM is sufficient for identifying uses of critical materials as an initial approach.

There are two perspectives on the problem of identifying critical materials in products. One approach could be to use a list of critical materials (for example the EC 14) and compare these with all product BOMs to identify any matches i.e. where a BoM lists a material of concern. This is necessary to identify all uses of critical materials within existing products, and is called the existing product perspective.

The opposite approach would be to start with a BoM and compare it with a list of critical materials to determine if any are used in the product. This is called the design perspective, where only those critical materials in the product being designed are of interest. The next sections focus on assessing the business risks posed by the use of critical materials approaching the problem from both the existing product and design perspectives.

\section{CASE STUDY 1: ASSESSING RISKS TO EXISTING PRODUCTS}

The following steps summarise the process for assessing the risks posed by critical materials to an existing product:

1. Identify at risk elements (the EC 14).

2. Identify if those elements are present in a product (required in order to understand the risk).

3. Complete a product based risk assessment by combining the measure of supply risk for the materials in question with the potential impact on business objectives from using the high risk material. To be relevant to existing design processes, the risk assessment has to be completed using the appropriate risk management criteria within Rolls-Royce.

PGMs were identified as having a high supply risk from the EC report. One particularly rare PGM is used as an alloying element within turbine blades on one of RollsRoyce's large civil aero-engines. Using an alloy with this PGM maintains high creep strength within blades that operate at very high temperatures and pressures [8].

When designing a component, several business objectives are set against which risk can be assessed. One of the main objectives is a target unit cost for the parts and engine. Risks to unit cost of using the PGM in turbine blades can therefore be assessed. Rolls-Royce applies $5 \times 5$ risk matrices combining measures of likelihood and impact to assess risk. The unit cost risk matrix relevant to the product being analysed is shown in Fig. 1.

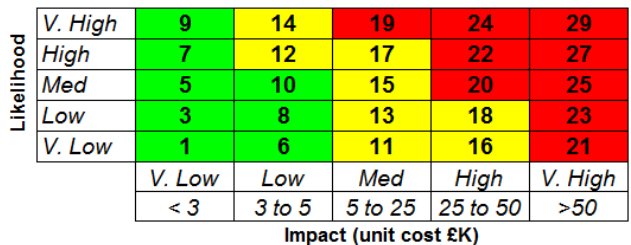

Fig. 1: Risk criteria case study 1

\section{Likelihood}

Assessing risk using the matrix in Fig. 1 requires the likelihood assessment method from the EC report to be translated into the scoring scheme applied, using a scale of $\mathrm{v}$. low to v. high. Based on the actual SR scores given in Table 2, Table 3 outlines how the SR translates into an assessment of likelihood consistent with the risk matrix.

Table 3: Translating SR scores into the risk matrix scale

\begin{tabular}{|c|c|}
\hline Likelihood (L) & SR score \\
\hline Very high & $\mathrm{SR} \geq 4$ \\
\hline High & $3 \leq \mathrm{SR}<4$ \\
\hline Medium & $2 \leq \mathrm{SR} \leq 3$ \\
\hline Low & $1 \leq \mathrm{SR}<2$ \\
\hline Very low & $\mathrm{SR}<1$ \\
\hline
\end{tabular}

PGMs having a SR score of 3.6 translates into a high likelihood from Table 3 . 


\section{Impact}

To assess the impact, a breakdown of unit cost is required to understand how much of the total cost of turbine blades the materials account for. Illustrative cost data is presented in Table 4.

Table 4: Illustrative unit cost breakdown

\begin{tabular}{|l|r|}
\hline Element & Cost (£s) \\
\hline Casting & 600 \\
\hline Material & 60 \\
\hline Coating & 250 \\
\hline Machining & 150 \\
\hline & $\mathbf{1 0 6 0}$ \\
\hline
\end{tabular}

An estimate of the potential cost increase of the material cost fraction is required, which is a function of:

1. How much the cost of the PGM could increase.

2. The PGM fraction of the whole material cost.

It is impossible to predict what the future cost of a material might be with any degree of certainty. To give an indication of the potential cost increase, the price volatility of the material is used. From company data the historical price volatility of the PGM in question is approximately 20 (calculated by dividing the maximum market price by the minimum taken over a 10 year period). For illustration, the PGM fraction of the cost of the material is estimated to be $1 / 3$. Thus the impact can be calculated by multiplying $1 / 3$ of the material price by 20 , shown in Table 5.

Table 5: Impact on unit cost

\begin{tabular}{|l|r|r|l|}
\hline Element & Cost (£s) & New cost (£s) & \\
\hline Casting & 600 & 600 & \\
\hline Material & 60 & $\mathbf{4 6 0}$ & \\
\hline Coating & 250 & 250 & \\
\hline Machining & 150 & 150 & \\
\hline & $\mathbf{1 0 6 0}$ & $\mathbf{1 4 6 0}$ & \\
\hline & & & Engine unit cost change \\
\hline & Change & 400 & $\mathbf{4 5 6 0 0}$ \\
\hline
\end{tabular}

As over 100 turbine blades are used in the engine, the total impact on unit cost of approximately $£ 45000$, which represents a high impact on the scale shown in Fig. 1.

\section{Risk assessment}

Combining the high likelihood from Table 3 with the impact calculated above produces the risk assessment result in Fig. 2.

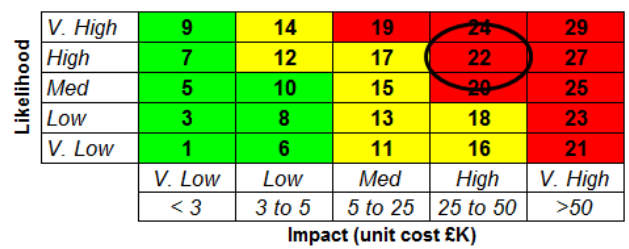

Fig. 2: Risk assessment result

Being the top right of the risk matrix this risk is deemed unacceptable and will require mitigating actions.

\section{Mitigating actions}

One mitigating action would be to take the PGM out of the blade. However, this will have an impact on specific fuel consumption (sfc), which is another design objective.
Risk criteria for assessing risks against sfe is shown in Fig. 3.

\begin{tabular}{|l|c|c|c|c|c|}
\hline V. High & 9 & 14 & 19 & 24 & 29 \\
\hline High & 7 & 12 & 17 & 22 & 27 \\
\hline Med & 5 & 10 & 15 & 20 & 25 \\
\hline \multirow{5}{\Xi}{ Low } & 3 & 8 & 13 & 18 & 23 \\
\hline V. Low & 1 & 6 & 11 & 16 & 21 \\
\hline \multicolumn{5}{|c|}{ Impact (specific fuel consumption \%) } \\
\cline { 2 - 6 } & V. Low & Low & Med & High & V. High \\
\cline { 2 - 6 } & $<0.03$ & 0.03 to 0.05 & 0.05 to 0.25 & 0.25 to 0.5 & $>0.5$ \\
\hline
\end{tabular}

Fig. 3: Risk criteria for sfc

The impact on sfc of taking the PGM out of the blade is estimated to be between $0.1-0.2 \%$, from internal engineering data. An sfc reduction of this magnitude translates into a medium impact using the $\mathrm{x}$-axis scale in Fig. 3.

As the impact on sfc will only occur if an alloy not containing the PGM is used, which is dependent on the likelihood of the PGM becoming unavailable, the likelihood result from the unit cost assessment is used. Combining this with the sfc impact produces the risk assessment result shown in Fig. 4.

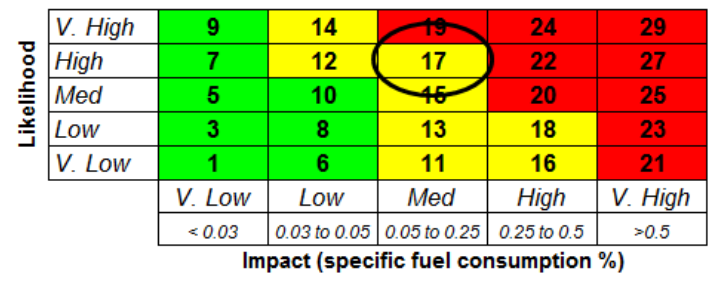

Fig. 4: Risk assessment result for sfc

As the risk to unit cost is higher than for sfc, on balance it is likely that the PGM would be removed and a different alloy used.

\section{CASE STUDY 2}

The following steps summarise the process for assessing the risks posed by the use of critical materials to new designs:

1. Select a BoM for a new design.

2. Identify critical materials used within the a BoM for a new design, by comparing it with the EC 14.

3. Complete product based risk assessment, using risk criteria relevant to the product in question, by multiplying the likelihood (supply risk) by the impact on business objectives.

A BoM for the outer liner of an annular combustor used on a small military turbofan engine is used for this case study, which is being re-designed to meet new customer requirements. Two uses of at risk elements were found in the new design:

1. Cobalt within the combustor alloy.

2. Yttrium (a REE), used within the thermal barrier coating applied to the combustor. 
As with the previous example, the case study will focus on the impact on unit cost objectives. The risk criteria taken from the relevant business risk management plan is shown in Fig. 5.

\begin{tabular}{|c|c|c|c|c|c|}
\hline \multirow{7}{*}{\begin{tabular}{|l} 
V. High \\
High \\
Med \\
Low \\
V. Low \\
\end{tabular}} & 9 & 14 & 19 & 24 & 29 \\
\hline & 7 & 12 & 17 & 22 & 27 \\
\hline & 5 & 10 & 15 & 20 & 25 \\
\hline & 3 & 8 & 13 & 18 & 23 \\
\hline & 1 & 6 & 11 & 16 & 21 \\
\hline & V. Low & Low & Med & High & V. High \\
\hline & $<0.6$ & 0.6 to 1 & 1 to 5 & 5 to 10 & $>10$ \\
\hline
\end{tabular}

Fig. 5: Risk assessment criteria

\section{Likelihood}

From Table 2, the SR scores for cobalt and yttrium are 1.1 and 4.9 respectively. These scores translate into a low likelihood for cobalt and very high likelihood for yttrium using Table 3.

\section{Impact}

The unit cost breakdown for the component is required to assess the impact on unit cost objectives. Illustrative cost data is given in Table 6 .

Table 6: Illustrative unit cost breakdown

\begin{tabular}{|l|r|}
\hline \multicolumn{1}{|c|}{ Element } & Cost (£s) \\
\hline Casting ops & 2500.00 \\
\hline Material & 500.00 \\
\hline Machining & 1250.00 \\
\hline Coating & 250.00 \\
\hline Remaining ops & 1500.00 \\
\hline & $\mathbf{6 0 0 0 . 0 0}$ \\
\hline
\end{tabular}

As with the previous case, to understand the impact on unit cost, an estimate of the potential cost increase of the material cost fraction is required, which is a function of:

1. How much the cost of the cobalt and yttrium could increase.

2. The cobalt and yttrium fraction of the overall material and coating costs.

From company data, the historical price volatility of cobalt is 6 (max. price/min. price over 10 years) and for yttrium is 7. For illustration, cobalt is estimated to represent $20 \%$ of the total material cost and yttrium 3\% of the coating cost. The impact is calculated by multiplying $20 \%$ of the materials cost by 6 (volatility of cobalt) and $3 \%$ of the coating cost by 7 (volatility for yttrium). The overall impact on cost is shown in Table 7.

Table 7: Unit cost impact

\begin{tabular}{|l|r|r|l|}
\hline \multicolumn{1}{|c|}{ Element } & Cost (£s) & New cost (£s) & \\
\hline Casting ops & 2500.00 & 2500.00 & \\
\hline Material & 500.00 & $\mathbf{1 1 0 0 . 0 0}$ & \\
\hline Machining & 1250.00 & 1250.00 & \\
\hline Coating & 250.00 & $\mathbf{3 0 2 . 5 0}$ & \\
\hline Remaining ops & 1500.00 & 1500.00 & \\
\hline & $\mathbf{6 0 0 0 . 0 0}$ & $\mathbf{6 6 5 2 . 5 0}$ & \\
\hline & & & Engine unit cost change \\
\hline & Change & 652.50 & \\
\hline
\end{tabular}

The impact on unit cost of $£ 600$ for cobalt represents a low impact on the scale shown in Fig. 5. Impact on unit cost of $£ 52.50$ for yttrium is very low using the same scale.

\section{Risk assessment}

Combining the low likelihood and impact for cobalt produces a low risk (Fig. 6). Combining the very high likelihood with a very low impact for yttrium also produces a low risk (Fig. 6). Aggregating the scores of impact and likelihood for both cobalt and yttrium gives a total materials criticality risk towards the centre of the risk matrix in Fig. 6. A risk of this magnitude is unlikely to be of concern, not requiring mitigating actions. Being towards the centre of the risk matrix it may require monitoring to ensure the risk does not become unacceptable.

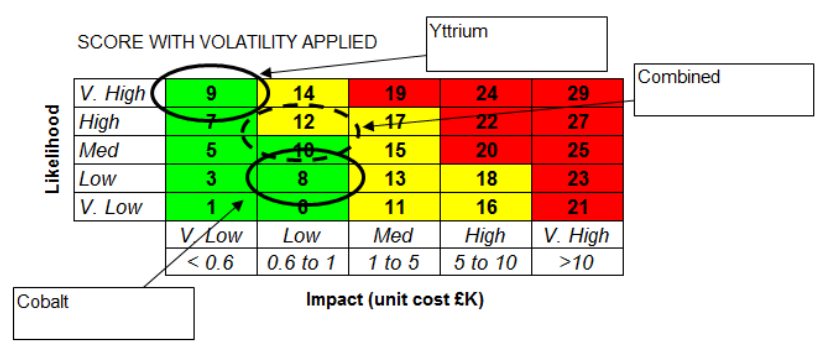

Fig. 6: Risk assessment result

\section{DISCUSSION}

The two case studies show how the risk based approach can be used to consider a complex environmental issue in a format that is consistent with standard engineering design decisions at Rolls-Royce. However, the approach is challenging for a number of reasons, discussed below.

There are significant uncertainties within all parts of the assessment. Firstly, assessing supply risk is not a simple task. The EC method was applied as it provided a transparent methodology and developing a bespoke approach was outside of the scope of this work. However, in reality there are many metrics that can be included within the assessment which were overlooked, for example risks related to materials produced as co-products or future changes in material demand. Adding both of these might have identified some of the 14 materials as being not critical, or highlighted at risk materials which have been overlooked. The method could be improved by selecting metrics that are relevant to the context (RollsRoyce), or even better using a dynamic modeling approach instead of relying on proxy metrics as representations of dynamic material supply systems [9].

Another area of uncertainty is in the product cost data used within the assessment. In a company with an extended supply chain, quite often a lot of the costs related to raw material inputs are not readily available. For the purposes of this paper illustrative costs were used. Although in practice cost data is difficult to get hold of. Costs can be estimated by comparing raw cost data from the purchasing function with cost breakdowns for parts. Engineering judgement can then be used to estimate what fraction of the cost of, for example a forging on a BoM, 
might be related to raw material inputs. Greater accuracy, and thus confidence in the results, could be obtained if the BoM (or other system) clearly outlined what costs elements were related to raw materials.

The most obvious area of uncertainty is predicting how a risk to supply may translate into an impact on cost. It is impossible to try and predict material prices. To obtain defendable estimates historical price volatility was used, although this must go with the caveat that relying on historical trends is a very poor means of estimating what might happen in the future [10]. For example, the price volatility for cobalt and yttrium were quite similar. Although the current price trend for cobalt is stable, while the shape of the yttrium curve is exponential. If this trend continued using past data is a very poor estimate of the future impact. This problem is not likely to be resolved; there are always going to be uncertainties in predicting the future.

A final source of uncertainty is in the business objectives themselves. Risk can only be assessed against objectives. If the business alters the criteria used for the risk assessment (the scales of impact, likelihood and acceptability of risks) the risks presented here could be more or less acceptable. Assessing risk is inherently subjective.

Acknowledging these uncertainties, the paper has shown how the risk based approach is useful. One classic problem in ecodesign is determining how to trade-off between environmental impacts. Using the framework of business objectives, the first case study successfully demonstrated how this can be achieved.

\section{EXPANDING THE RISK BASED APPROACH}

A final consideration is how the risk approach could be expanded to include other environmental business hazards. Building from the two perspectives described in Section 3.2 , this could be achieved by defining more features of environmental hazards (for example the use of hazardous substances). This would also require more detailed product data containing features of products that could be connected to these hazards, with a life cycle view (for example, a life cycle inventory). Ways of measuring the likelihood of different hazards will also be required.

\section{CONCLUSIONS}

This paper has presented an approach to ecodesign based on environmental risk management, in conclusion:

- The risk based approach successfully demonstrates how a complex environmental problem could be considered with standard engineering decisions. It has also shown that by using business objectives, environmental impacts can be traded off with each other.
- However, whilst the method was successful, there were significant uncertainties. In particular assessing supply risk and how this translates into an impact on material price.

- The risk based approach could be expanded to include other environmental business hazards. This requires more detailed product data.

\section{REFERENCES}

[1] BSI (2009): Risk management - principles and guidelines, British Standards Institution (BSI), London.

[2] Matten, D. (1995): Strategy follows structure: environmental risk management in commercial enterprises, Business Strategy and the Environment, 4, pp. 107-116.

[3] Pennington, D.W., Potting, J., Finnveden, G., Lindeijer, E., Jolliet, O., Rydberg, T., Rebitzer, G. (2004): Life cycle assessment part 2: Current impact assessment practice, Environment International, 30, pp. 721-739.

[4] Graedel, T.E. (2007): Determining the criticality of materials, UNEP International Workshop on resource efficiency and recycling, Tokyo, September, United Nations Environment Programme (UNEP).

[5] Morley, N., Eatherley, D. (2008): Material secturity: Ensuring resource availability for the UK economy, C-Tech Innovation, Chester, UK.

[6] Duclos, S., Otto, J.P., Konitzer, D.G. (2010): Design in an era of constrained resources. Mechanical Engineering, American Society of Mechanical Engineers (ASME), September.

[7] European Commission (2010): Critical raw materials for the EU, European Commission, Brussels.

[8] Koizumi, Y., Kobayashi, T., Jianxin, Z., Yokokawa, T., Harada, H., Aoki, Y. and Arai, M. (2003): Development of next generation Ni-base single crystal superalloy. Proceedings of the International Gas Turbine Congress, Tokyo, 2-7 November, Gas Turbine Society of Japan.

[9] Alonso, E. (2010): Materials scarcity from the perspective of manufacturing firms: risks, effects and responses, $\mathrm{PhD}$ Thesis, Massachusetts Institute of Technology, Cambridge, MA, USA.

[10] Taleb, N., Goldstein, D.G., Spitznagel, M.W. (2009): The six mistakes executives make in risk management, Harvard Business Review, October, pp. $78-81$. 